Check for updates

Cite this: Mater. Adv., 2020, 1,1705

Received 26th March 2020 Accepted 14th July 2020

DOI: 10.1039/d0ma00134a

rsc.li/materials-advances

\section{Differential antimicrobial and cellular response of electrolytically metalized halloysite nanotubes having different amounts of surface metallization}

\begin{abstract}
Ahmed Humayun, ${ }^{a}$ Yangyang Luo, ${ }^{a}$ Anusha Elumalai ${ }^{\mathrm{ab}}$ and David K. Mills (D) *ab
We demonstrate an electrolytic method to metalize the outer surface of halloysite nanotubes (HNTs). Different metal HNT (mHNT) combinations (copper, silver, zinc) were produced with metal content in the 5-30 wt\% range. mHNTs were characterized using a Scanning Electron Microscope (SEM), energydispersive spectroscopy (EDS), X-ray fluorescence (XRF), Fourier-transform infrared spectroscopy (FTIR) and X-ray powder diffraction (XRD). Different amounts of surface/lumen metal content of a system can confer differing antimicrobial/cellular response; hence, it is essential to assess the antimicrobial/cellular response as a function of metal content. Cellular response after exposure to mHNTs was studied in Staphylococcus aureus and pre-osteoblasts, respectively. Coated mHNTs could easily be identified using the characterization methods, and contrasting bacterial and cellular responses were obtained, which we propose was due to the extent of metallization. These findings demonstrate the potential of this method for creating metal-coated HNTs and suggest they have potential as an implant coating solution.
\end{abstract}

\section{Introduction}

Due to increased incidences of microbial infections and rising microbial resistance to antibiotics, innovative antimicrobial agents are the need of the present age. ${ }^{1-3}$ Metal nanoparticles (NPs) exhibit significant antimicrobial activity by themselves ${ }^{4-6}$ as well as a synergistic activity when combined with other antimicrobial agents, ${ }^{7,8}$ however, their utility is restricted due to their inherent instability leading to agglomeration and thus a reduction in potency. Furthermore, at high concentrations their cytotoxic effects outstrip the antimicrobial potential. ${ }^{9}$

Metals NPs and oxides inhibit bacterial growth by inducing oxidative stress and the production of reactive oxygen species. ${ }^{10}$ Metal NPs, including silver, zinc, and copper NPs are used commercially due to low cost, abundance, and relatively less toxicity; however, owing to extremely high surface energy, they agglomerate into larger particles, thereby diminishing the desired effects. ${ }^{11}$ This situation can be resolved by using surfactant materials such as polyvinylpyrrolidone, polyethylene glycol, and sodium citrate, however, this has proven to be a temporary band-aid fix at best due to associated high costs, intricate pre and post-processing steps and possible eco-toxicity. ${ }^{12}$ HNTs can be a viable solution to this problem as they can

\footnotetext{
${ }^{a}$ School of Biological Sciences and the Center for Biomedical Engineering and Rehabilitation Science, Louisiana Tech University, Carson Taylor Hall, Room 128, Ruston, LA, 71272, USA. E-mail: dkmills@latech.edu; Fax: +1-318-257-4574; Tel: +1-318-257-2640

${ }^{b}$ School of Biological Sciences, Louisiana Tech University, Ruston, LA, 71272, USA
}

adsorb metal NPs, thus reduce their agglomeration ${ }^{13}$ and potentiate a more sustained metal NPs release in a system by desorption, and therefore increase the likelihood of achieving more pragmatic utilities and results. Previous investigations confirm that metal NPs, when adsorbed on HNTs, retain their antimicrobial properties. ${ }^{9,14,15}$

Halloysite nanotubes (HNTs), are a dioctahedral 1:1 nano clay made of rolled-up layers of aluminosilicate sheets, it is 500-1000 nm long, $50 \mathrm{~nm}$ diameter with 15-50 nm lumen, it occurs throughout the world and is biocompatible, ${ }^{16}$ further, it is of significant interest due its high adsorption capacity, ${ }^{17}$ unique surfaces, and lumen charge polarity chemistry, nontoxic nature, ${ }^{18}$ wide distribution, and low cost. ${ }^{19}$ It has been incorporated in corrosion-resistant coatings $\mathrm{s}^{20,21}$ and fireretardant materials. ${ }^{22,23}$ Due to its charged hollow lumen it is used as a container for various chemicals including drugs, ${ }^{16,24-26}$ dyes, ${ }^{27,28}$ and metals, ${ }^{30}$ in recent years it has generated interest as an adsorbent surface for various antimicrobial, ${ }^{29}$ catalytic, ${ }^{31,32}$ and heavy metal remediation, ${ }^{33}$ as a filler for structural modification in bone cements, ${ }^{34-36}$ dental fillings, ${ }^{37}$ and polymer additive. ${ }^{38-40}$

The deposition of metal NPs on HNTs is a straightforward process because of their inherent adsorbent ability, which can be further enhanced using chemical modifications. In this study, we employed a modified electrolytic method for metalizing HNTs based on a process previously described by Mills et al. ${ }^{41}$ We used several electrolytic parameters to regulate the behavior of metal nanoparticles in the electrolytic system in order to influence metal NPs density, interacting, with the 
HNTs. NP adsorption onto the HNT surface would also be directly affected. As different amounts of metal content in a structure can confer contrasting antimicrobial/cellular responses, it is also essential to assess the antimicrobial and cellular response as a function of metal content.

In this study, we demonstrate an electrolytic synthesis of reduced metal species, their subsequent adsorption on HNTs' outer surface, and study its contrasting antimicrobial and cellular response in Staphylococcus aureus and preosteoblast cell, respectively as a function of the nature and quantity of metal deposition on HNTs external surface. Different mHNTs ( $\mathrm{m}=$ silver, copper, or zinc) were synthesized electrolytically having metal content within 5-30 wt\% range at two different voltages 5 and $20 \mathrm{~V}$ respectively and characterized using SEM, energy-dispersive spectroscopy (EDS), X-ray fluorescence (XRF), Fourier-transform infrared spectroscopy (FTIR), UV-Visible spectroscopy, and X-ray powder diffraction (XRD).

\section{Materials and methods}

\subsection{Materials}

Staphylococcus aureus (S. aureus) $\mathrm{ATCC}^{\circledR} 6538^{\mathrm{TM}} 50 \mathrm{CFU}, \mathrm{AgNO}_{3}$, $\mathrm{CuSO}_{4}, \mathrm{ZnSO}_{4} \cdot 7 \mathrm{H}_{2} \mathrm{O}$ (99.9\% pure), HNTs, ethanol, acetone, propanol, methanol, live-dead kit, Mueller Hinton broth, and agar were purchased from Sigma-Aldrich (St Louis, MO). Resazurin dye was obtained from Cayman Chemicals (Ann Arbor, MI), DC power source (VWR Accupower 500 electrophoresis power supply), platinum mesh electrodes, plastic Petri dishes, and ammeter (TekPower TP9605BT) were purchased from Amazon.com LLC (Seattle, WA). Resazurin dye from Cayman Chemicals (Ann Arbor, MI), Live/Dead ${ }^{\mathbb{R}}$ viability/ cytotoxicity kit and cryomedium from Thermo Fisher Scientific (Waltham, MA).

\subsection{Electrolytic metallization of HNTs}

mHNTs were prepared using a modified protocol based on an electrolytic metallization procedure previously described by Mills et al. ${ }^{1}$ Briefly, an electrolysis setup was assembled consisting of two platinized titanium mesh held parallel at 2 in distance and connected to a DC power source (VWR Accupower 500) (Fig. 1). Ultrasonicated $100 \mathrm{~mL}$ aqueous solution of metal salts (2.5 mM) and $50 \mathrm{mg}$ HNT were dispersed in a glass beaker, and voltages of 5 and $20 \mathrm{~V}$ respectively were maintained at $80{ }^{\circ} \mathrm{C}$ with polarity reversal every 5 min intervals ${ }^{2}$ with constant magnetic stirring to reduce electrophoretic buildup at the working electrode and thus increase reduced species density

(a) Halloysite nanotubes (HNTs) structure

(Outer surface - negatively charged)

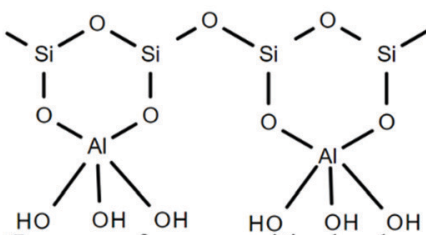

(Inner surface - positively charged)

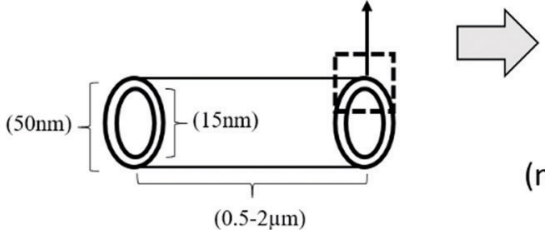

Halloysite nanotube (HNTs)

(d)Differential antimicrobial activity
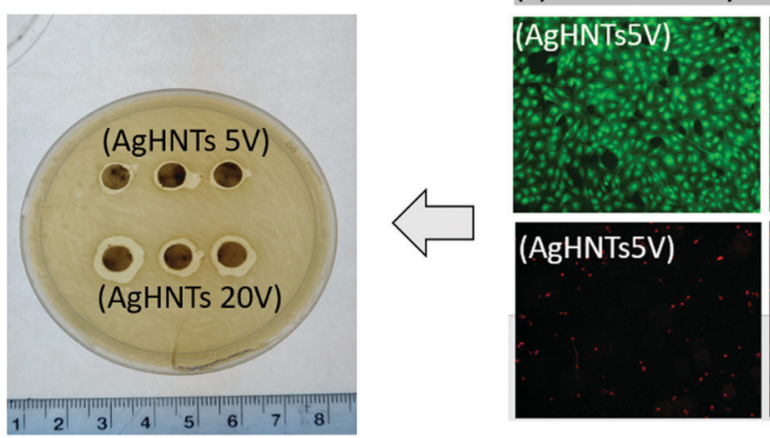
Process

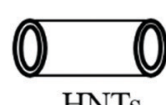

(metal NPs)
(b)Electrolytic

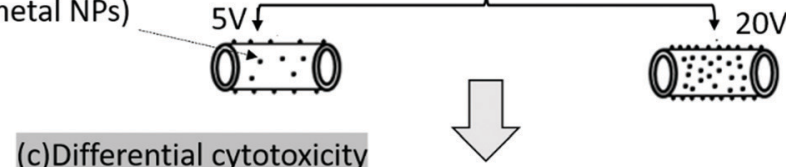

(c)Differential cytotoxicity
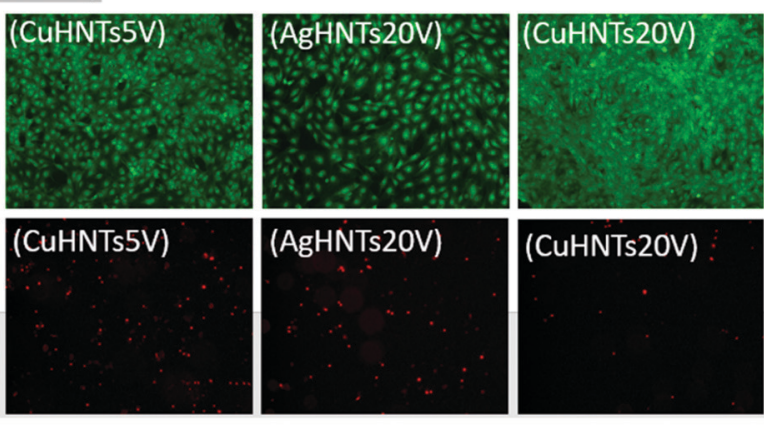

Fig. 1 Description of the metal coating process (a) HNT chemical structure, morphology, and SEM-EDS graph, (b) electrolytic process for metallizing HNTs at 5 and $20 \mathrm{~V}$ respectively, (i) cathodic migration of silver ions, (ii) cathodic reduction and release of neutral silver nanoparticles into the solution, (iii) adsorption of silver nanoparticles on the outer surface of HNTs, (c) contrasting cytotoxicity of mHNTs made at 5 and $20 \mathrm{~V}$, (d) contrasting antimicrobial activity of mHNTs fabricated at $5 \mathrm{~V}$ and $20 \mathrm{~V}$. 
in the solution. Then, the supernatant was decanted three times and the solution was centrifuged at $5000 \mathrm{rpm}$ for $5 \mathrm{~min}$ with water to separate out mHNTs from un-adsorbed metal particles and dried at $30{ }^{\circ} \mathrm{C}$.

\subsection{Characterization}

Hitachi S-4800 field-emission SEM (Tokyo, Japan) was used to examine the surface morphology of the coated HNTs and to visually confirm the presence of the metal coating appearing as clusters on the otherwise smooth HNT outer surface. SEM-EDS were carried out with an EDAX energy dispersive X-ray analyzer linked to the HITACHI S-4800 SEM to evaluate the elemental composition and weight percentage (wt\%) deposition on the AgHNTs. EDS was operated at a working distance of $15 \mathrm{~mm}$ and an acceleration voltage of $15 \mathrm{kV}$; EDS spectra were analyzed using the EDAX Genesis software.

X-ray crystal diffraction analysis was recorded on a Bruker D8 Venture diffractometer (Bruker, Karlsruhe, Germany) with $\mathrm{Cu} \mathrm{K} \alpha 1$ radiation $(\lambda=1.5418 \AA)$. The scan speed and step size used were $2 \mathrm{~s}$ and $0.02^{\circ}$ respectively, the diffraction patterns were recorded on a Philips PW 1710 X-ray powder diffractometer over $2 \theta$ within $3^{\circ}$ to $85^{\circ}$.

The samples were analyzed using a Thermo/ARLQuant'X energy dispersive X-ray fluorescence spectrometer. The X-ray tube was operated at $30 \mathrm{kV}$ for 60 live seconds, using a $0.05 \mathrm{~mm}$ (thick) $\mathrm{Cu}$ primary beam filter in an air path for silver metal detection. The XRF spectra were studied using Wintrace $7.1^{\mathrm{TM}}$ software (Thermo Fisher Scientific, Waltham, MA).

The infrared spectrum was recorded at a resolution of $4 \mathrm{~s}^{-1}$ with 16 scans using a Thermo Scientific NICOLET ${ }^{\mathrm{TM}}$ IR100 FT-IR Spectrometer (Thermo Fisher Scientific; Waltham, MA). Thermo Scientific OMNIC ${ }^{\mathrm{TM}}$ software was used to study the stretching bands.

UV spectra of the silver nanoparticles were recorded using the NanoDrop-2000c spectrophotometer (Thermo Fisher Scientific, Waltham, MA) set at a 250-600 nm scan range. Microplate absorbances were analyzed using Biotek 800TS microplate reader (Winooski, VT) set at $630 \mathrm{~nm}$ absorbance.

Antibacterial activity. $S$. aureus was used in this study; it was maintained in tryptic soy agar. For testing, the bacterial strain was cultured in nutrient broth and plated on Muller-Hinton agar plates at $37^{\circ} \mathrm{C}$ overnight after which a single colony was picked up using a sterile toothpick and suspended in saline solution and diluted to $0.5 \mathrm{McF}$ arland standard $\left(1.5 \times 10^{8} \mathrm{CFU} \mathrm{mL}^{-1}\right)$, $20 \mu \mathrm{L}$ of which was spread over Muller-Hinton agar plates on which the test materials were placed and incubated for $18 \mathrm{~h}$ at $37{ }^{\circ} \mathrm{C}$ and the obtained zones of inhibition were analyzed using ImageJ software.

mHNTs discs for antimicrobial assay were prepared. Here, $6 \mathrm{~mm}$ discs were punched from Whatman \# three filter paper, and $1 \mathrm{mg}$ of mHNTs in $2 \mathrm{~mL}$ ethanol was gradually infused using an automatic pipette, the discs were dried in an incubator at $37^{\circ} \mathrm{C}^{3}$ and plated on Mueller-Hinton agar plates spread plated with $20 \mu \mathrm{L}$ of $0.5 \mathrm{McF}$ arland $S$. aureus and incubated at $37^{\circ} \mathrm{C}$ overnight in an incubator.

A resazurin assay was used for qualitative minimum inhibitory concentration determination, where, $0.25 \mathrm{mg}$ of mHNTs were serially diluted in $100 \mu \mathrm{L}$ of Mueller Hinton broth and inoculated with $10 \mu \mathrm{L}$ of $1 \times 10^{5} \mathrm{CFU} \mathrm{mL}^{-1}$ of $S$. aureus Grampositive bacteria and incubated in wells of a 96 well plate at $30{ }^{\circ} \mathrm{C}$ for $6 \mathrm{~h}$ after which $20 \mu \mathrm{L}$ of $0.0015 \mathrm{wt} / \mathrm{v} \%$ resazurin aqueous solution was added to each well. Live bacteria cells reduce the blue non-fluorescent resazurin to pink fluorescent resorufin, thus providing a direct analysis of the bacterial metabolic activity. ${ }^{4}$

Cell culture. Cell viability response after exposure to mHNTs was studied using pre-osteoblast cells (MC3T3), which were obtained from the American Type Culture Collection (ATCC).

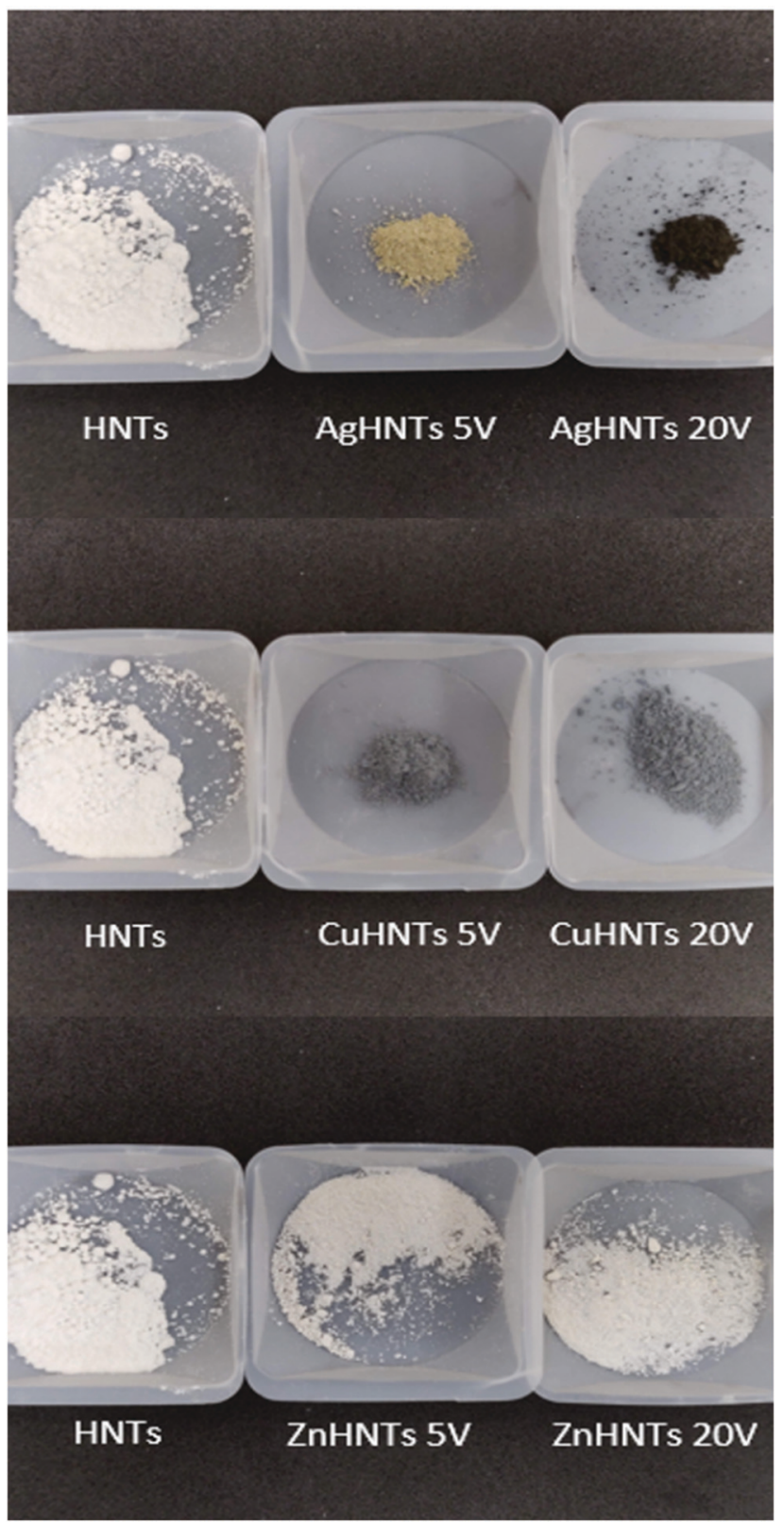

Fig. 2 The natural white color of the HNTs was altered to darker colors depending on the type of metal used and quantity adsorbed, which can be attributed to the adsorption of darker color metal NPs on HNTs exterior surface. 

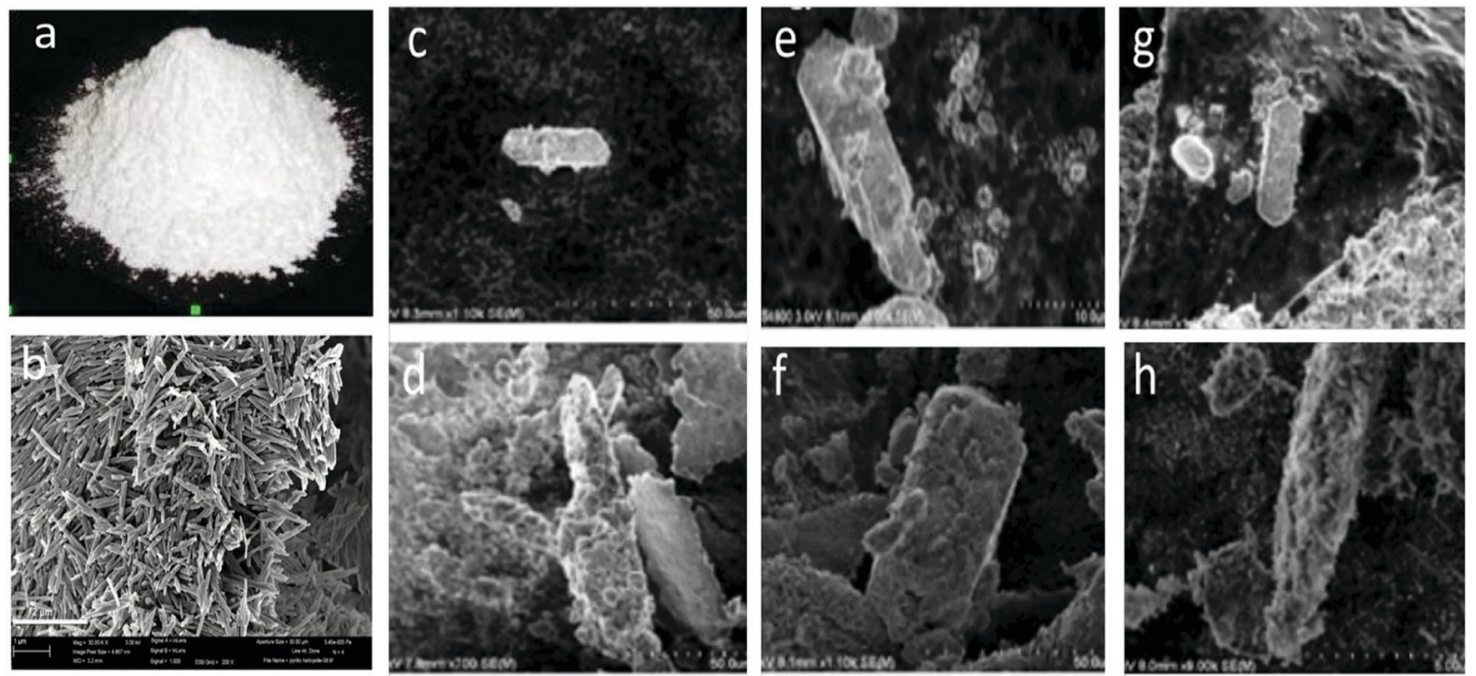

Fig. 3 (a) Photograph of HNT powder and its traditional white color; (b) SEM of HNTs; SEM micrographs (c-h); (c and d) AgHNTs 5 and 20 V, (e and f) CuHNTs 5 and $20 \mathrm{~V}$, and (g and h) Zn HNTs 5 and $20 \mathrm{~V}$ respectively.

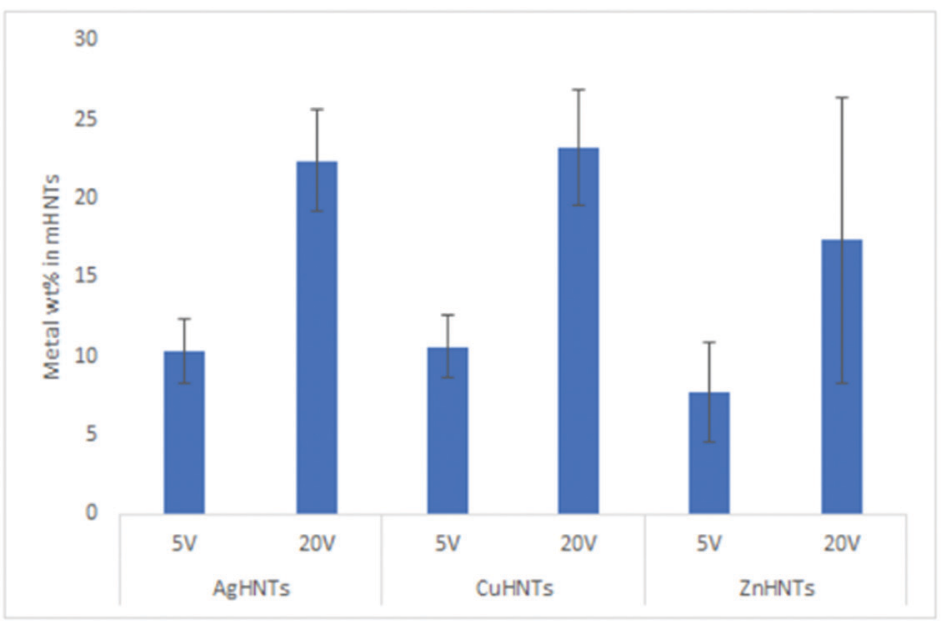

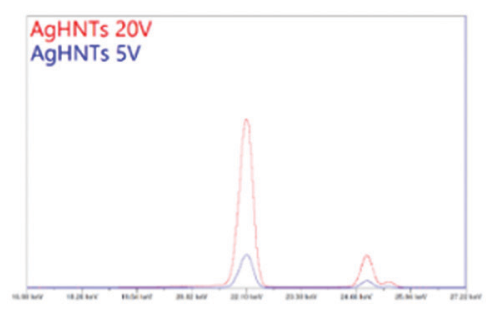

XRF intensity spectra of AgHNTs

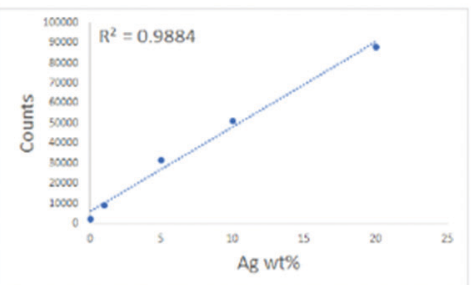

XRF intensity Vs. Ag wt\% trendline

$X R F$ quantitative analysis of $m H N T S$

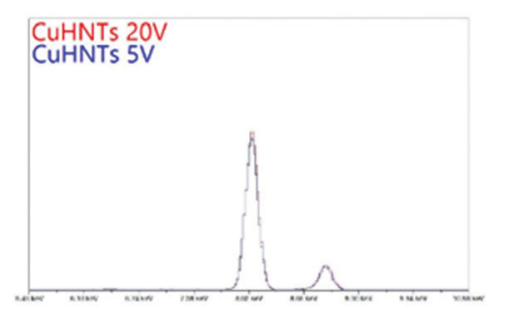

XRF intensity spectra of CuHNTs

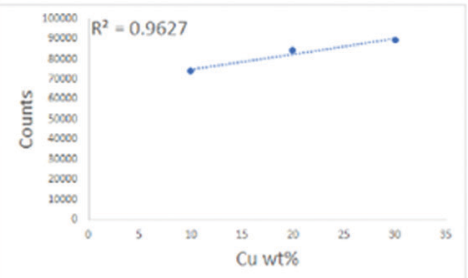

XRF intensity Vs. Cu wt\% trendline

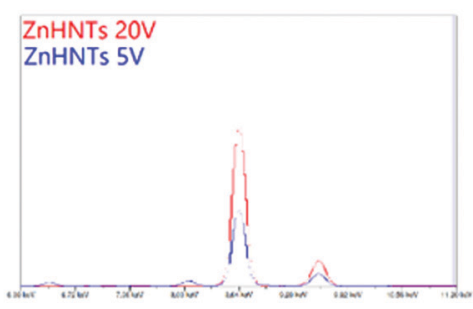

XRF intensity spectra of ZnHNTs

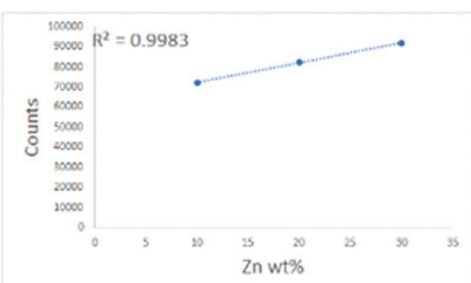

XRF intensity Vs. Zn wt\% trendline

Fig. 4 XRF quantitative analysis of $\mathrm{Ag}, \mathrm{Cu}$, and ZnHNTs, respectively. Adsorbed metal content in mHNTs increased with applied voltage (5 and $20 \mathrm{~V}$ ). (error bar indicates standard deviation $p<0.05$ ). 
a

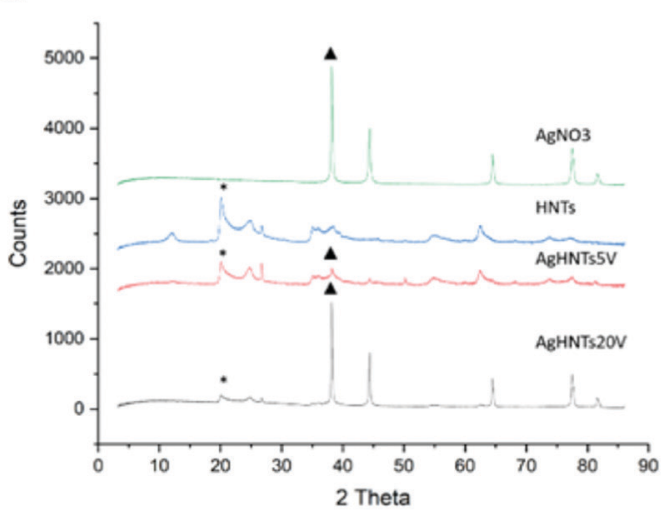

b

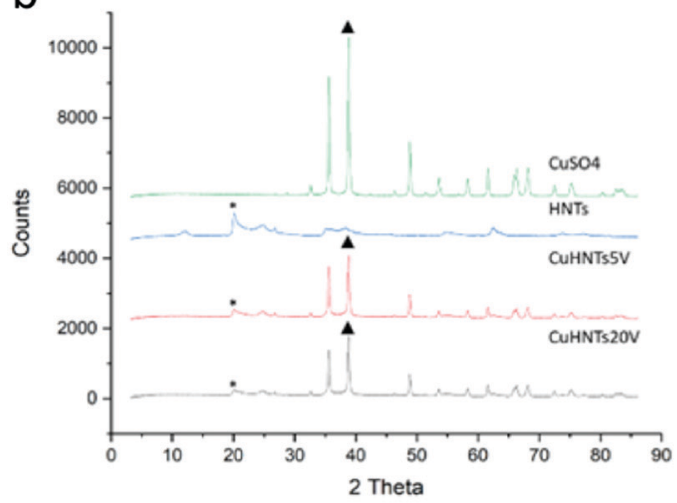

C

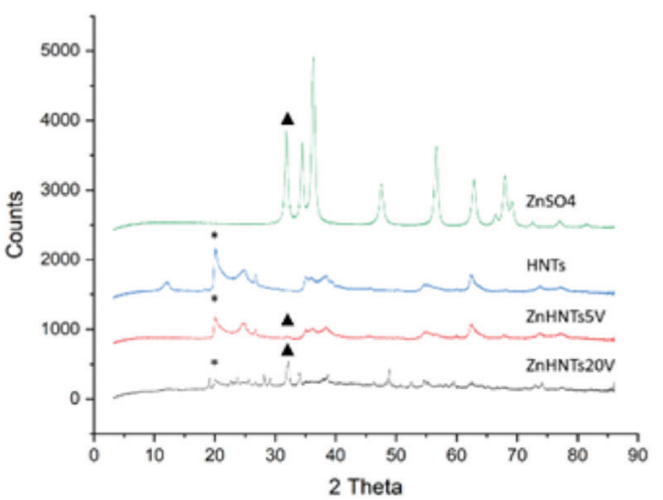

FTIR

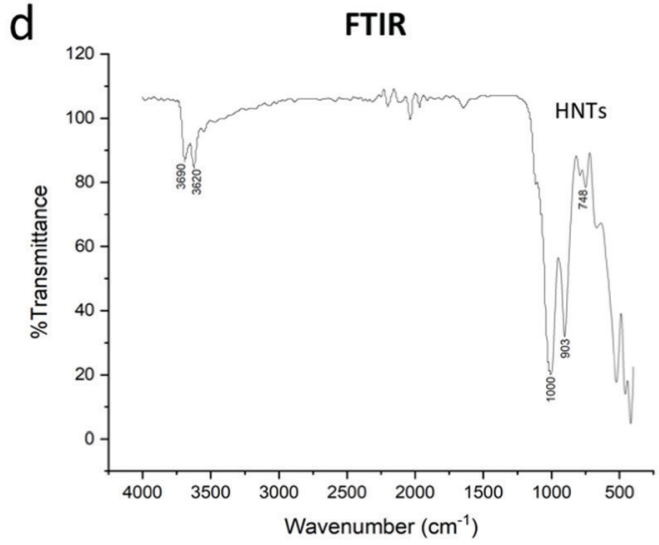

Fig. 5 XRD spectra of AgHNTs (a), CuHNTs (b), and ZnHNTs (c). (d) FTIR pattern of as received HNTs displaying the characteristic FTIR pattern.

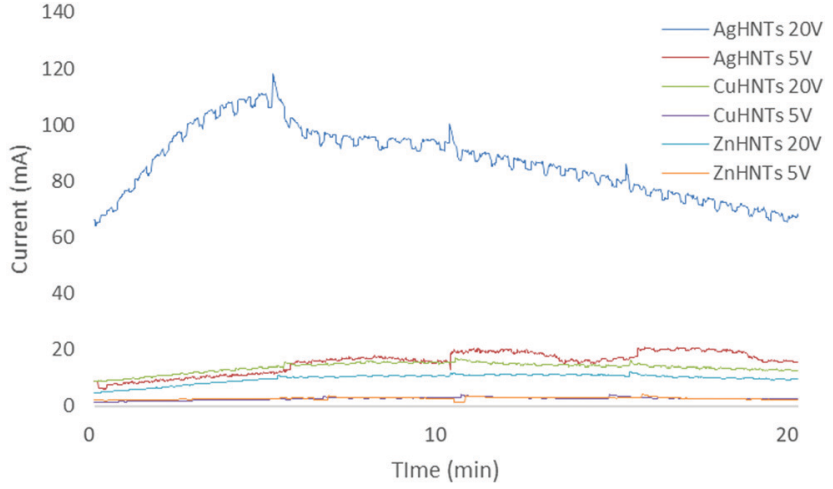

Fig. 6 Current $(\mathrm{mA})$ vs. time $(\mathrm{min})$ for mHNTs samples in aqueous electrolytic setup, the amount of current flow recorded as a function of the conductivity of the individual metal salts, solvents, and applied voltage.

Cryovial was thawed and allowed to equilibrate in a water bath with $37{ }^{\circ} \mathrm{C}$, then cells were cultured in T25 flasks in complete alpha-MEM containing 10\% FBS and 1\% penicillin (complete medium) and incubated at $37{ }^{\circ} \mathrm{C}$ under humidified $5 \% \mathrm{CO}_{2}$ and 95\% air incubator. Cells through passage four and then frozen down and maintained in a liquid nitrogen Dewar until used. A trypsin-EDTA $(0.25 \%$ trypsin, $1 \mathrm{mM}$ EDTA $)$ was used to detach cells from the culture flasks.
For each experiment $(n=3)$, passage four pre-osteoblasts were thawed and resuspended in complete medium, prepared as described above, and used when they achieved sub-confluency. Cytotoxicity tests and cell proliferation tests were performed by pre-seeding cells in 48-well plates at a concentration of $1 \times 10^{5}$ cells per well and cultured for 24 hours. Cells were then rinsed with HBSS and incubated in complete medium with mHNTs at $20 \mu \mathrm{g} \mathrm{mL} \mathrm{m}^{-1}$ for a $24 \mathrm{~h}$ duration. Pre-osteoblast cultures without exposure to mHNT were used as control.

Live/dead cytotoxicity tests. Pre-osteoblast cells were cultured and tested with mHNT as described above. Cell viability was assessed using a LIVE/DEAD ${ }^{\circledR}$ Viability/Cytotoxicity Kit (ThermoFisher) containing polyanionic dye calcein, which is retained within living cells and produces an intense uniform green fluorescence (excitation/emission $\sim 495 \mathrm{~nm} / \sim 515 \mathrm{~nm}$ ) and EthD-1, which enters cells with damaged membranes and produces a bright red fluorescence in dead cells (ex/em $\sim 495 \mathrm{~nm} / \sim 635 \mathrm{~nm}$ ).

For viability studies, the staining solution was prepared by mixing $5 \mu \mathrm{L}$ of $4 \mathrm{mM}$ Calcein AM Solution and $20 \mu \mathrm{L}$ of $2 \mathrm{mM}$ EthD-III Solution to $10 \mathrm{~mL}$ of DPBS. Cell culture plates were washed twice with HBSS, and then $50 \mu \mathrm{L}$ of staining solution was added to each well plate. These substrates were then incubated at room temperature for $30 \mathrm{~min}$. Each cytotoxicity experiment was repeated three times. Images were captured 

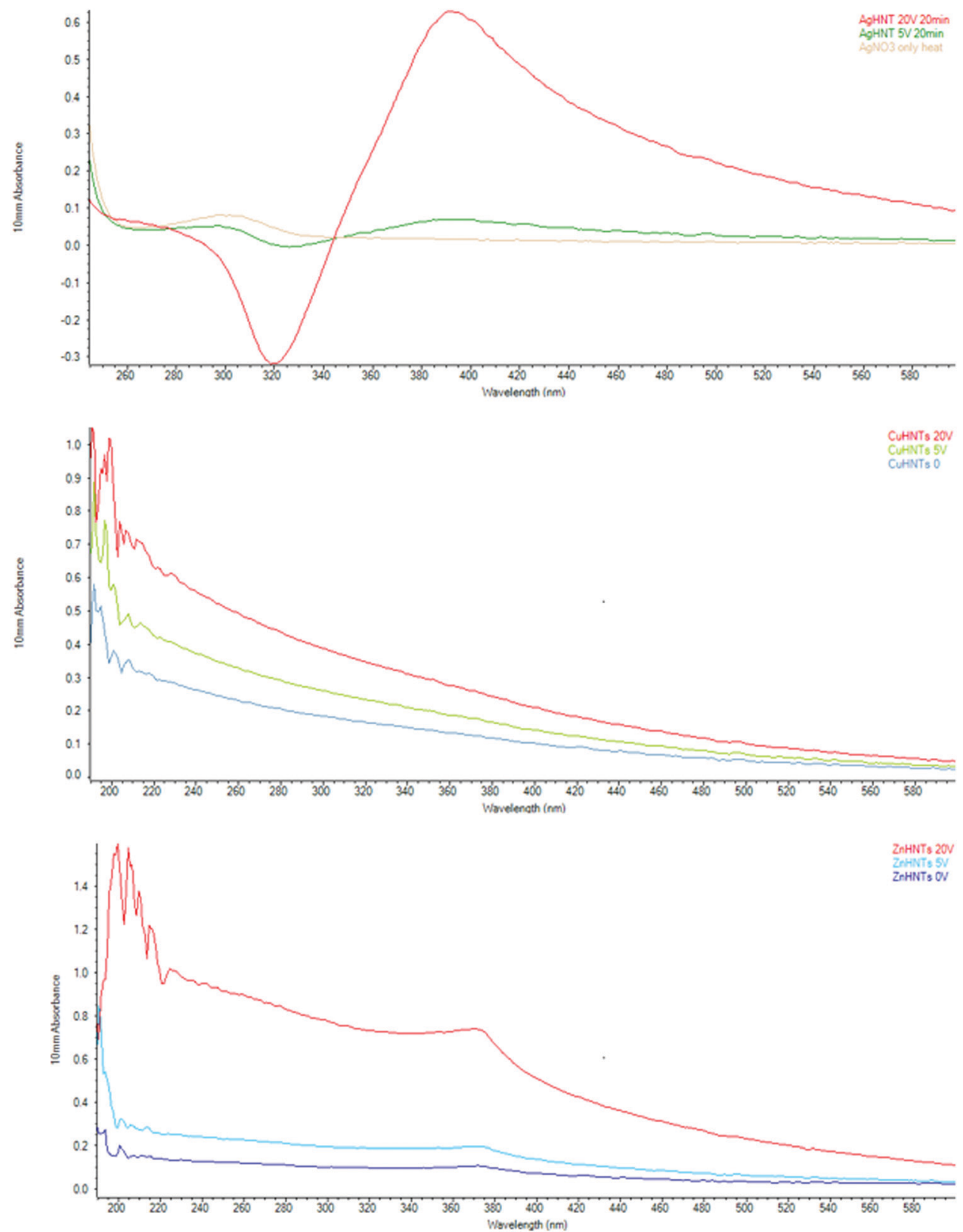

Fig. 7 UV-Vis spectra of mHNTs ( $m=\mathrm{Ag}$, Zn, or Cu, respectively). Peaks were observed for Ag, Cu, and Zn at 420, 228, and 360 nm respectively.

using an Olympus BX51 fluorescence microscope (Olympus Corporation, Tokyo, Japan) equipped with an Olympus DP11 digital camera system. Image ${ }^{5}$ was used for counting fluorescent cells from thresholded 8bit images at a cell size limit of 50-200 pixel $^{2}$.

Cell proliferation studies. Cell proliferation was assessed using MTS colorimetric assay, which is based on the reduction of MTS tetrazolium compound to a colored formazan product soluble in culture media. $40 \mu \mathrm{L}$ of MTS reagent was added to each well and incubated at $37{ }^{\circ} \mathrm{C}$ for 2 hours. $200 \mu \mathrm{L}$ of supernatant of each well were transferred to 96 well plates and read absorbance values at $490 \mathrm{~nm}$, background absorbance was subtracted from the medium wells containing the medium as a control.
Statistical analysis. Statistical analysis was performed using Microsoft Excel Analysis ToolPak plugin and Origin 9.6. Linear regression was used to construct and correlate standard curves. All experiments were done in triplicate, and one-way analysis of variance (ANOVA) with $p<0.05$ as the significance level was utilized for statistical analysis. Statistically significant data was reported $(p<0.05)$, and all the results were reported as mean \pm standard deviation $(p<0.05, n=3)$ unless otherwise specified.

\section{Results and discussion}

mHNTs with varying metal content were synthesized by application of 5 and $20 \mathrm{~V}$, which could easily be distinguished by 


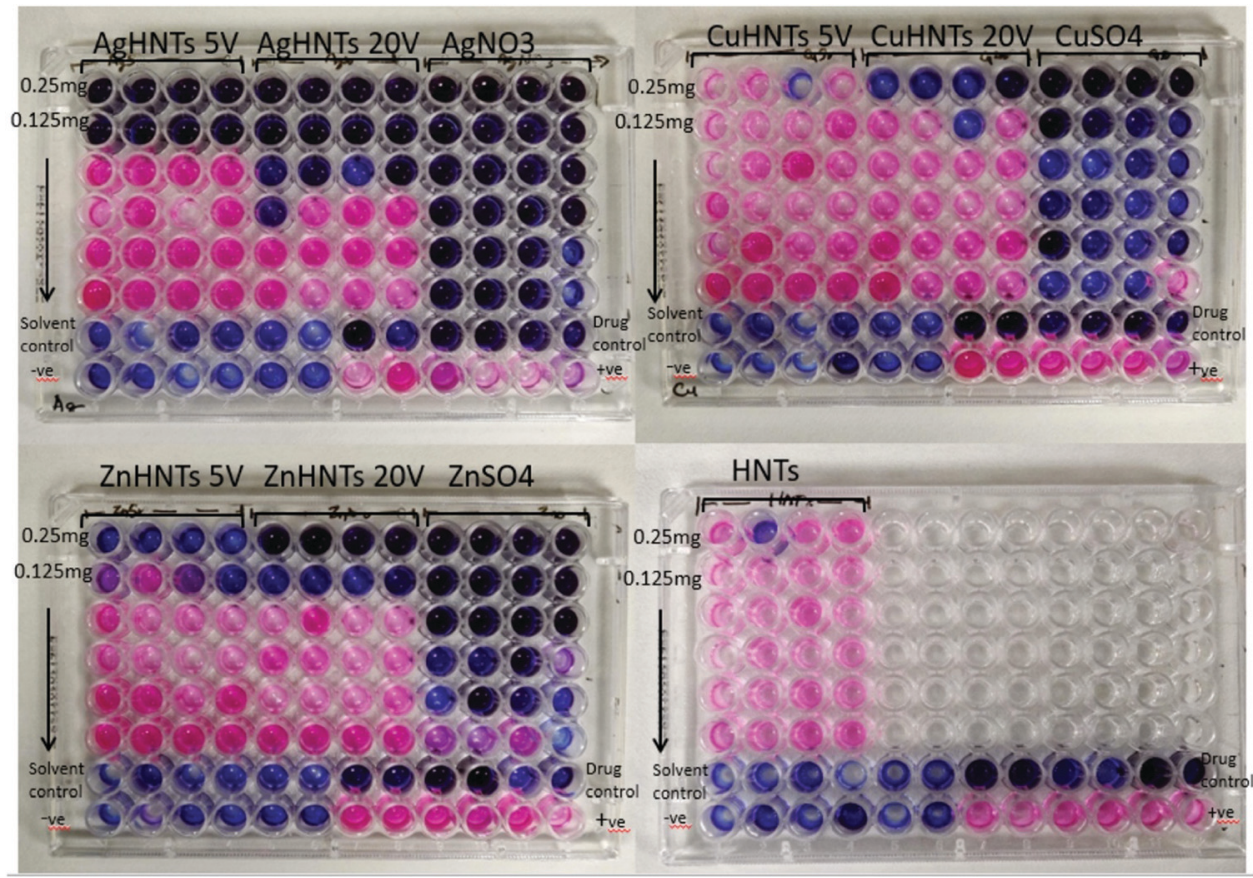

Fig. 8 Determination of MIC for mHNTs against S. aureus using resazurin assay. Purple well corresponds to dead, whereas partially purple/pink, and pink wells correspond to live bacteria, $(n=4)$.
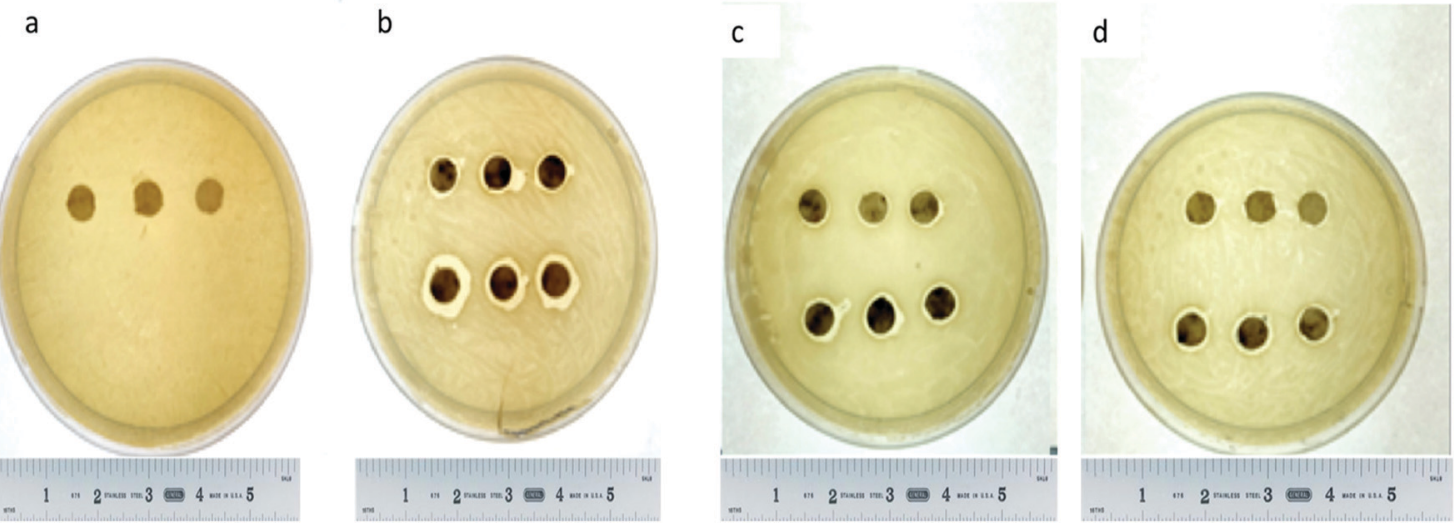

Fig. 9 Disc diffusion assay of (a) HNTs, (b) AgHNTs, (c) CuHNTs, (d) ZnHNTs, (5 V - top, $20 \mathrm{~V}$ - bottom.

visual analysis of the obtained samples, which turned darker with an increasing metal content as shown in Fig. 2.

SEM-EDS analysis revealed a positive correlation between applied voltage and metal content (wt\%) in mHNTs, which can be observed in terms of increased surface deposition on an otherwise smooth HNT, which increased with the applied voltage, brief patches of HNT surface were visible at $5 \mathrm{~V}$ however at $20 \mathrm{~V}$ the surface of MHNT was covered with irregular patches (Fig. 3).

These findings were confirmed using XRF, where an increasing amount of metal content was observed as a function of voltage increment (Fig. 4). A similar trend was observed in the XRD spectra, where increasing respective metal peak intensities were observed with increased metal content. In general, higher applied voltage samples displayed stronger corresponding metal and subdued halloysite peaks, respectively, whereas low voltage samples exhibited the contrary, i.e., stronger halloysite and weaker metal peaks respectively (Fig. 5a-c). In another study constructed $\mathrm{Ag}-\mathrm{ZnO}-\mathrm{HNTs}$, where different amounts of ZnO metallization was achieved by using varying amounts of zinc precursor salts for reduction and similar gradation in the XRD, were obtained, ${ }^{6}$ similar results were obtained when HNTs were mixed with varying amounts of titanium dioxide. ${ }^{7}$

FTIR analysis of HNTs showed the inner and outer layer $\mathrm{Al}-\mathrm{OH}$ stretching at 3690 and $3620 \mathrm{~cm}^{-1}$, in-plane $\mathrm{Si}-\mathrm{O}-\mathrm{Si}$ stretching at $1000 \mathrm{~cm}^{-1}$ and $1091 \mathrm{~cm}^{-1}$ and, symmetric $\mathrm{Si}-\mathrm{O}-\mathrm{Si}$ stretching at $748 \mathrm{~cm}^{-1}$ (Fig. 5d). Amperage was recorded, and higher currents were detected for higher voltages (Fig. 6), which can be explained as being due to a higher ionization of metal salt electrolytes leading to increased ionic density in the solution resulting in an increased population of metal 


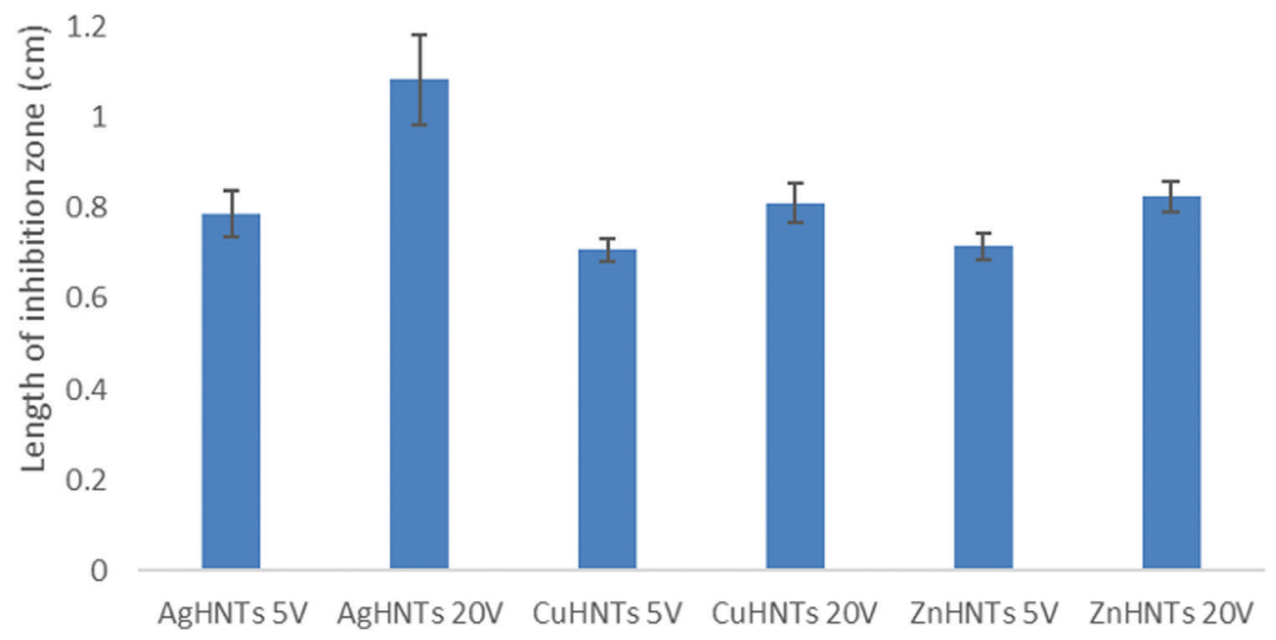

Fig. 10 Inhibition zones from the disc diffusion assay. AgHNTs $20 \mathrm{~V}$ exhibited significant greater inhibition zone compared to all other groups. Higher metal content mHNTs exhibited greater inhibition zones: AgHNTs $20 \mathrm{~V}>$ AgHNTs $5 \mathrm{~V}$; CuHNTs $20 \mathrm{~V}>$ CuHNTs 5 V; ZnHNTs $20 \mathrm{~V}>$ ZnHNTs 5 V. (Error bar indicates standard deviation; $n=3, p \leq 0.05$.)

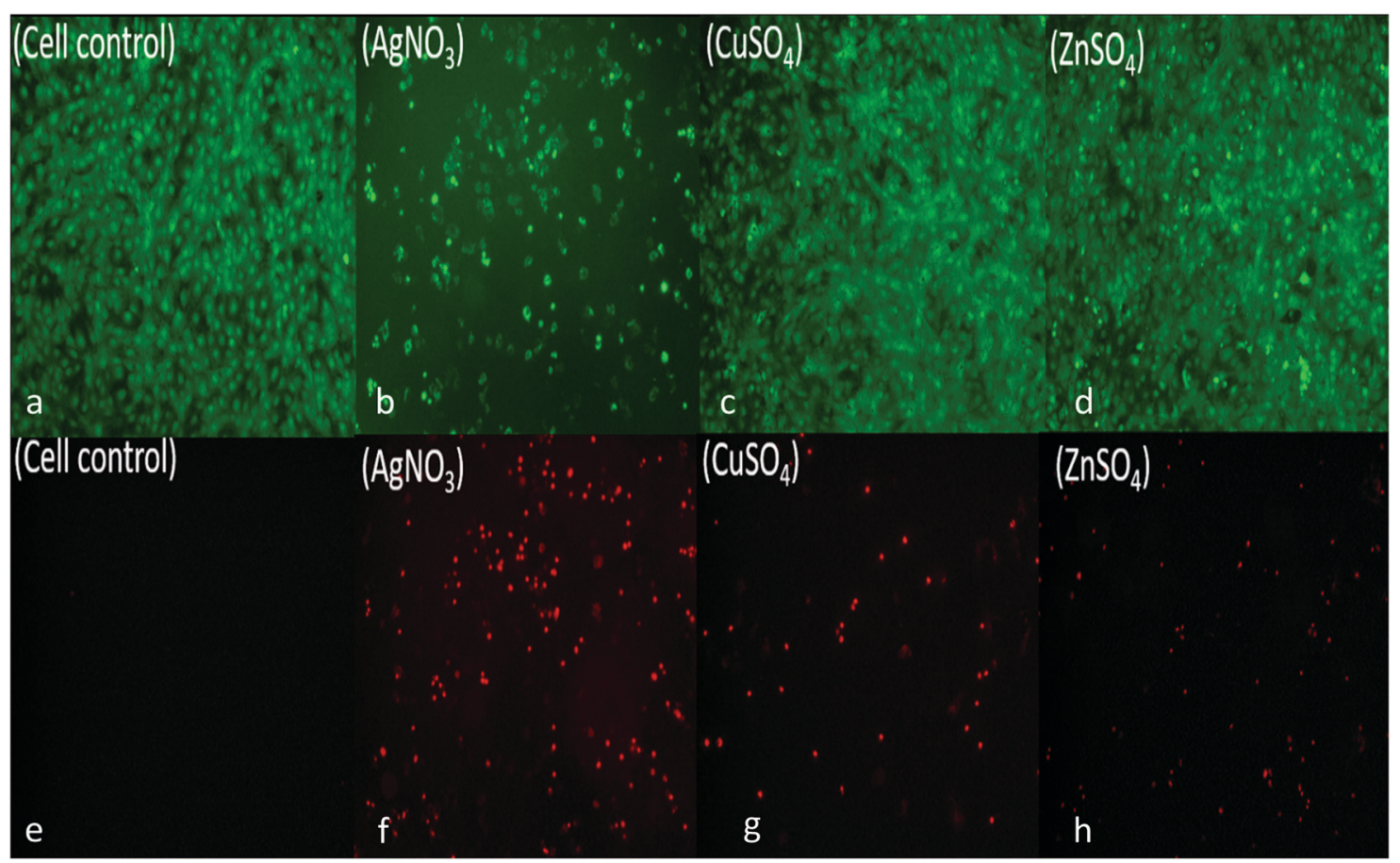

Fig. 11 Live/dead assay; pre-osteoblast cells were cultured in the presence of metal salts ( $\mathrm{a}$ and e) untreated cell control, (b and f) $\mathrm{AgNO}_{3}$, (c and g) $\mathrm{CuSO}_{4}$, (d and h) $\mathrm{ZnSO}_{4}$ salts. Live cells (green), dead cells (red).

nanoparticles interacting with HNTs surface leading to corresponding increased metal $\mathrm{wt} \%$ in mHNTs with increased applied voltage. Previous studies have shown a reduction in the mean particle size of silver with an increase in current density. ${ }^{8,9}$

A similar trend was observed with UV analysis, an increase in NPs concentration for silver, copper, and zinc NPs, respectively, with an increasing voltage at 420,228 , and $360 \mathrm{~nm}$, respectively (Fig. 7). Nanoparticles due to a collective oscillation of the conduction electrons exhibit absorption of visible electromagnetic waves, this is referred to as the surface plasmon resonance effect, this phenomenon is of particular interest because it enables the possibility of metal NPs detection and size analysis using UV-vis spectroscopy. ${ }^{10}$

Previous studies have shown that silver NPs size can be controlled electrochemically, ${ }^{8}$ and antimicrobial action is strongly size dependent, ${ }^{11}$ and a strong correlation between 


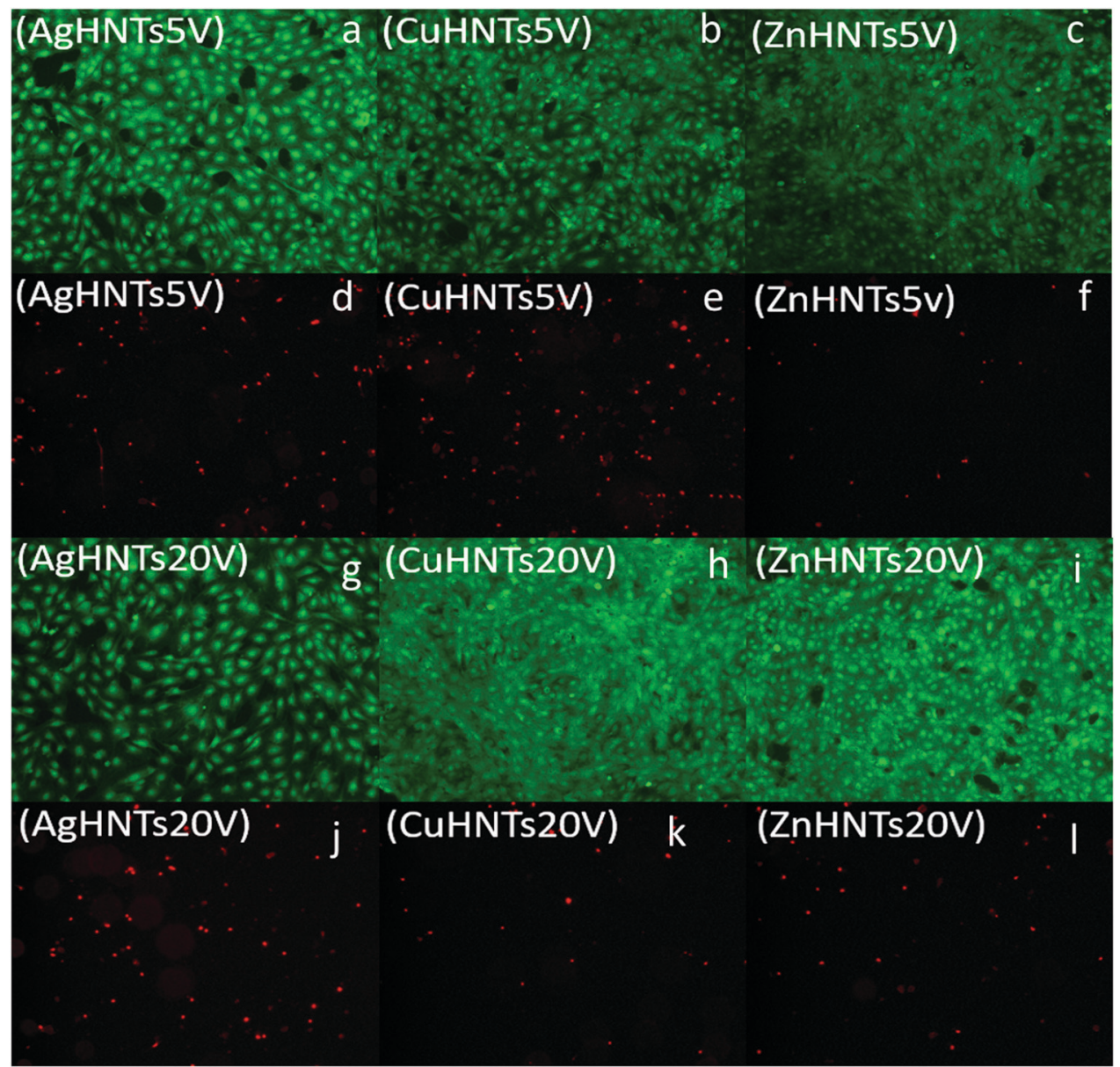

Fig. 12 Live/dead assay. Pre-osteoblast cells were cultured in the presence of mHNTs (a, d, g and j) AgHNTs 5 and 20 V, (b, e, h and k) CuHNTs 5 and $20 \mathrm{~V}$, (c, f, I nd l) ZnHNTs 5 and $20 \mathrm{~V}$ respectively. Live cells (green) and dead cells (red).

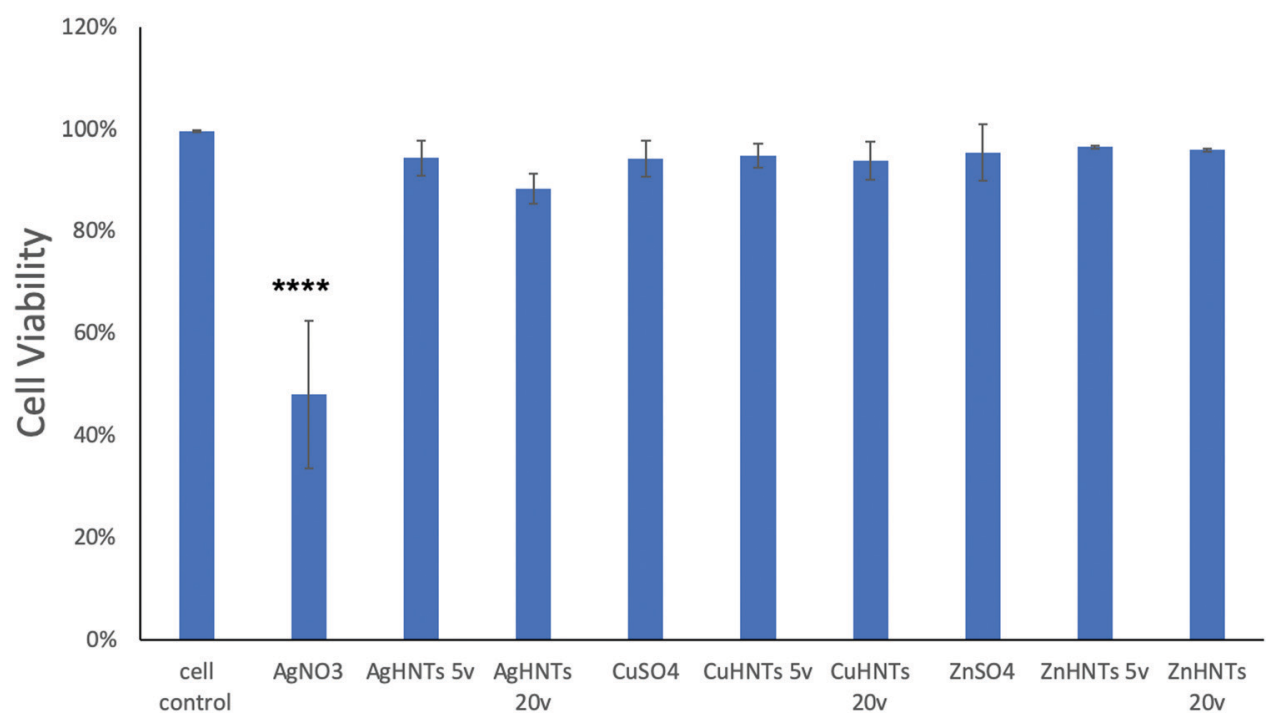

Fig. 13 Cell viability assay for mHNTs. $\mathrm{AgNO}_{3}$ was found to be most toxic to cellular viability, and the toxicity reduced when adsorbed to HNTs. (Error bar indicates standard deviation, $n=3, * * * * p 0.0001$.) 


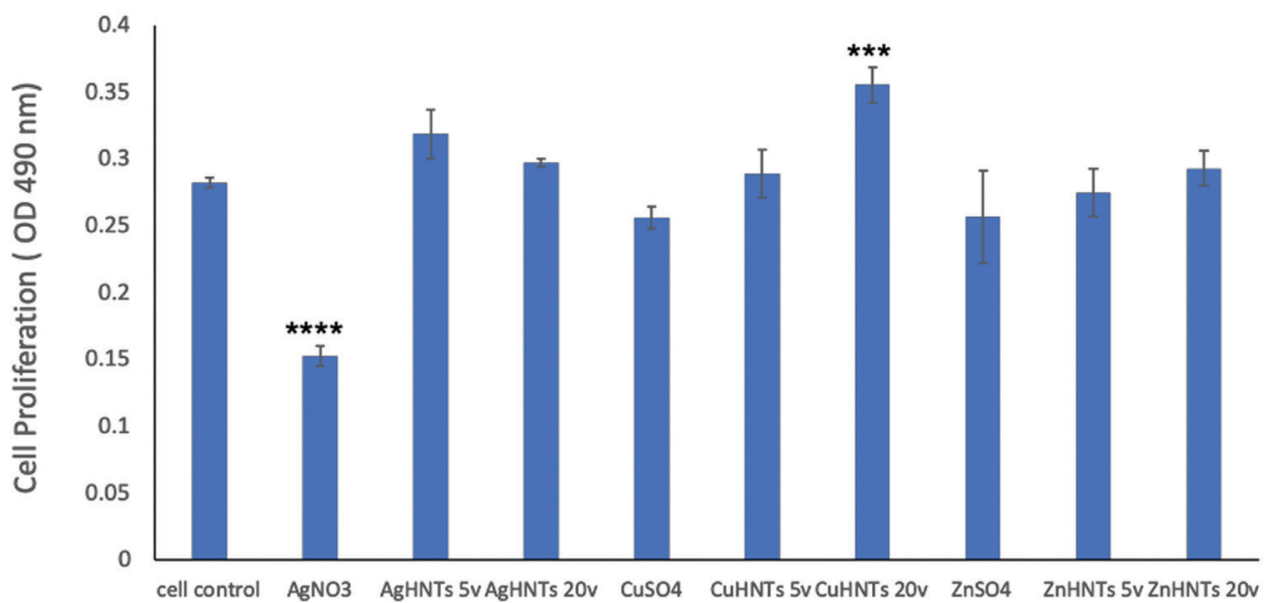

Fig. 14 Cell proliferation assay for mHNTs, CuHNTs and ZnHNTs displayed increased cellular proliferation while AgHNTs displayed reduced cell proliferation with increased metal concentration adsorbed on HNTs (error bar indicates standard deviation, $n=3,{ }^{\star \star \star \star} p<0.0001$; ${ }^{\star \star \star} p<0.001$ ).

silver NPs and UV-visible absorbance exists. ${ }^{12}$ Similarly, Zn NPs have been reported to display a strong absorption peak at $360 \mathrm{~nm} \cdot{ }^{13-15}$ Similarly, Cu NPs can also be detected and are size quantifiable using UV-Vis spectroscopy. ${ }^{16}$

mHNTs were evaluated for antimicrobial effect on $S$. aureus using the resazurin dye assay, a positive correlation was observed between observed minimum inhibitory concentration (MIC, at least 3 out of a total of 4 wells are dark blue in appearance, $n=4$ ) and metal content of mHNTs. MICs for AgHNTs (0.25 and $0.125 \mathrm{mg} \mathrm{mL}^{-1}$ respectively), CuHNTs (none and $0.25 \mathrm{mg} \mathrm{mL}^{-1}$ respectively), and ZnHNTs ( 0.125 and $0.25 \mathrm{mg} \mathrm{mL}^{-1}$ respectively) at 5 and $20 \mathrm{~V}$ respectively were observed (Fig. 8).

A disc diffusion assay was performed using agar plating (Fig. 9) mHNTs $20 \mathrm{~V}$ had greater average zones of inhibitions than mHNTs at $5 \mathrm{~V}$ due to their higher metal content (Fig. 10).

To assess for any potential cytotoxicity issues, preosteoblasts were co-cultured with free metal particles and cell viability significantly decreased in the presence of $\mathrm{AgNO}_{3}$ (Fig. 11 and 13). Ag NPs have been reported to be cytotoxic and genotoxic, ${ }^{17}$ size-dependent toxicity has also been reported. ${ }^{18}$ One study also reported that Ag NPs damage the eukaryotic DNA by affecting the ATP content. ${ }^{19}$ In the process of electrolytic metallization on HNTs, higher metal accumulation was observed in the 20 voltage treatment with reduced silver content at 5 volts (Fig. 3). Therefore, AgHNTs (20 V) contain more Ag NPs than AgHNTs (5 V). Due to the cytotoxicity of Ag NPs, an increased amount of AgNPs results in decreased cell viability (Fig. 12, AgHNTs (20 V) vs. AgHNTs (5 V)). CuHNTs and ZnHNTs exhibited insignificant contrast for both voltages in terms of cell viability; however, displayed there was a significant difference in cellular proliferation tests.

In contrast, $\mathrm{Zn}$ and $\mathrm{Cu}$ NPs have been demonstrated in several studies to be cell supportive. One study reported that low concentration exposure of copper NPs led to increased cellular proliferation in rat cerebral endothelial cells, whereas toxicity was observed at higher concentrations. ${ }^{20}$ Another study reported the angiogenesis promoting the ability of copper NPs. ${ }^{21}$ ZnO NPs have remarkably been shown to have exhibited selective cytotoxicity to cancer cells and none towards normal cells; ${ }^{22}$ another study reported minimal cytotoxicity to human $\mathrm{T}$ cells at levels toxic to prokaryotes. ${ }^{23}$ A similar trend was observed in our cell proliferation studies (Fig. 14).

The results of these studies are consistent with our hypothesis, the nature and the quantity of a specific metal deposited on the HNT surface has an influence over the antimicrobial response and cytotoxicity of mHNTs.

\section{Conclusion}

Several methods exist for metalizing HNTs; however, they are limited in scope as the extent of HNT metallization cannot be controlled, which, as demonstrated above, is a vital parameter in surface metallization. We demonstrated the electrolytic synthesis of metal-coated HNTs (mHNTs) with varying degrees of surface metallization that displayed contrasting antimicrobial and cellular response from Staphylococcus aureus and pre-osteoblasts, respectively. Metalizing the HNT's exterior surface and the quantity of metal decoration as a function of the applied voltage was achieved. We anticipate that future developments leading to the deposition of more than two metals will open up potentially novel biomedical applications when combined with halloysite's proven ability to release a range of drugs over a sustained period.

\section{Author contributions}

The authors all contributed to the writing of the manuscript. A. H., Y. L., and A. E. conducted the experiments under the direction of D. K. M. All authors reviewed and analyzed the data.

\section{Conflicts of interest}

The authors declare no conflict of interest. 


\section{Acknowledgements}

Mr Davis Bailey and Dr Sven Eklund for training. Funding for this study was provided by a grant (to Dr Mills) from the Louisiana Biomedical Research Network (through an Institutional Development Award (IDeA) from the National Institute of General Medical Sciences of the National Institutes of Health under grant number P20 GM103424-17 and Center for Dental, Oral \& Craniofacial Tissue \& Organ Regeneration (C-DOCTOR) with the support of NIH NIDCR (U24DE026914). The authors also wish to acknowledge the support of the College of Applied and Natural Sciences (Louisiana Tech University) Matching Grant Program (DKM) and the China Scholarship Council (YL).

\section{References}

1 D. Mills and C. Boyer, US Pat. 9981074B1, 2018.

2 R. A. Khaydarov, R. R. Khaydarov, O. Gapurova, Y. Estrin and T. Scheper, J. Nanopart. Res., 2009, 11, 1193-1200.

3 J. Kramer and A. Kirshbaum, Appl. Environ. Microbiol., 1961, 9, 334-336.

4 M. Elshikh, S. Ahmed, S. Funston, P. Dunlop, M. McGaw, R. Marchant and I. M. Banat, Biotechnol. Lett., 2016, 38, 1015-1019.

5 C. A. Schneider, W. S. Rasband and K. W. Eliceiri, Nat. Methods, 2012, 9, 671.

6 Z. Shu, Y. Zhang, Q. Yang and H. Yang, Nanoscale Res. Lett., 2017, 12, 135.

7 A. Rapsomanikis, D. Papoulis, D. Panagiotaras, E. Kaplani and E. Stathatos, Global NEST J., 2014, 16, 485-498.

8 L. Rodriguez-Sanchez, M. C. Blanco and M. A. Lopez-Quintela, J. Phys. Chem. B, 2000, 104, 9683-9688.

9 L.-P. Jiang, A.-N. Wang, Y. Zhao, J.-R. Zhang and J.-J. Zhu, Inorg. Chem. Commun., 2004, 7, 506-509.

10 S. Link and M. A. El-Sayed, Annu. Rev. Phys. Chem., 2003, 54, 331-366.

11 G. A. Martinez-Castanon, N. Nino-Martinez, F. MartinezGutierrez, J. R. Martinez-Mendoza and F. Ruiz, J. Nanopart. Res., 2008, 10, 1343-1348.

12 R. Desai, V. Mankad, S. K. Gupta and P. K. Jha, Nanosci. Nanotechnol. Lett., 2012, 4, 30-34.

13 A. Yadav, V. Prasad, A. A. Kathe, S. Raj, D. Yadav, C. Sundaramoorthy and N. Vigneshwaran, Bull. Mater. Sci., 2006, 29, 641-645.

14 M. M. AbdElhady, Int. J. Carbohydr. Chem., 2012, 840591.

15 A. K. Zak, R. Razali, W. H. A. Majid and M. Darroudi, Int. J. Nanomed., 2011, 6, 1399.

16 G. Angajala, P. Pavan and R. Subashini, RSC Adv., 2014, 4, 51459-51470.

17 P. V. AshaRani, G. Low Kah Mun, M. P. Hande and S. Valiyaveettil, ACS Nano, 2008, 3, 279-290.

18 M. V. D. Z. Park, A. M. Neigh, J. P. Vermeulen, L. J. J. de la Fonteyne, H. W. Verharen, J. J. Briedé, H. van Loveren and W. H. de Jong, Biomaterials, 2011, 32, 9810-9817.

19 L.-Y. Wong, J. Recht and B. C. Laurent, J. Mol. Histol., 2006, 37, 261-269.
20 W. J. Trickler, S. M. Lantz, A. M. Schrand, B. L. Robinson, G. D. Newport, J. J. Schlager, M. G. Paule, W. Slikker, A. S. Biris and S. M. Hussain, Nanomedicine, 2012, 7, 835-846.

21 N. Mroczek-Sosnowska, E. Sawosz, K. Vadalasetty, M. Łukasiewicz, J. Niemiec, M. Wierzbicki, M. Kutwin, S. Jaworski and A. Chwalibog, Int. J. Mol. Sci., 2015, 16, 4838-4849.

22 L. Taccola, V. Raffa, C. Riggio, O. Vittorio, M. C. Iorio, R. Vanacore, A. Pietrabissa and A. Cuschieri, Int. J. Nanomed., 2011, 6, 1129.

23 K. M. Reddy, K. Feris, J. Bell, D. G. Wingett, C. Hanley and A. Punnoose, Appl. Phys. Lett., 2007, 90, 213902.

24 G. Cavallaro, et al., J. Phys. Chem. C, 2015, 119(16), 8944-8951.

25 Y. Lvov, W. Wang, L. Zhang and R. Fakhrullin, Adv. Mater., 2016, 28, 1227-1250.

26 G. Cavallaro, G. Lazzara, S. Milioto, F. Parisi, V. Evtugyn, E. Rozhina and R. Fakhrullin, ACS Appl. Mater. Interfaces, 2018, 10, 8265-8273.

27 S. Patel, U. Jammalamadaka, L. Sun, K. Tappa and D. K. Mills, Bioengineering, 2015, 3(1), 1.

28 M. Massaro, G. Lazzara and R. Noto, et al., Rend. Fis. Acc. Lincei, 2020, 31, 213-221.

29 G. Gorrasi, Carbohydr. Polym., 2015, 127, 47-53.

30 Y. Liu, J. Zhang, H. Guan, Y. Zhao, J.-H. Yang and B. Zhang, Appl. Surf. Sci., 2018, 427, 106-113.

31 S. Barrientos-Ramírez, E. V. Ramos-Fernández, J. SilvestreAlbero, A. Sepúlveda-Escribano, M. M. Pastor-Blas and A. González-Montiel, Microporous Mesoporous Mater., 2009, 120, 132-140.

32 A. Glotov, A. Stavitskaya, Y. Chudakov, E. Ivanov, W. Huang, V. Vinokurov, A. Zolotukhina, A. Maximov, E. Karakhanov and Y. Lvov, Bull. Chem. Soc. Jpn., 2019, 92(1), 61-69.

33 A. A. Hermawan, J. W. Chang, P. Pasbakhsh, F. Hart and A. Talei, Appl. Clay Sci., 2018, 160, 106-115.

34 W. Wei, E. Abdllayev, A. Goeders, A. Hollister, L. Lvov and D. K. Mills, Macromol. Mater. Eng., 2012, 297, 645-653.

35 U. Jammalamadaka, K. Tappa, J. A. Weisman, J. C. Nicholson and D. K. Mills, Nanotechnol., Sci. Appl., 2017, 10, 105-114.

36 U. Jammalamadaka, K. Tappa and D. K. Mills, Calcium phosphate/clay nanotube bone cement with enhanced mechanical properties and sustained drug release, in Clay Science and Engineering, ed. M. Zoveidavianpoor, InTech Publishers, 2018.

37 D. A. Cunha, N. S. Rodrigues and L. C. Souza, et al., Materials, 2018, 11(7), 1080.

38 M. Liu, C. Wu, Y. Jiao, S. Xiong and C. Zhou, J. Mater. Chem. B, 2013, 1(15), 20782089.

39 X. Zhao, C. Zhou and M. Liu, J. Mater. Chem. B, 2020, 8(5), 838-851.

40 K. Roy, S. C. Debnath, A. Pongwisuthiruchte and P. Potiyaraj, Appl. Clay Sci., 2019, 183, 105300.

41 D. K. Mills and C. Boyer, Method for metalizing nanotubes through electrolysis, US Pat., 9981074B1, 2018. 